\title{
Apatitic calcium phosphates: Synthesis, characterization and reactivity in the removal of lead(II) from aqueous solution
}

\author{
Doan Pham Minh ${ }^{\mathrm{a}, *}$, Haroun Sebei ${ }^{\mathrm{a}}$, Ange Nzihou ${ }^{\mathrm{a}}$, Patrick Sharrock ${ }^{\mathrm{b}}$ \\ ${ }^{a}$ Université de Toulouse, Mines Albi, CNRS, Centre RAPSODEE, Campus Jarlard, F-81013 Albi Cedex 09, France \\ ${ }^{\mathrm{b}}$ Université de Toulouse, SIMAD, IUT Paul Sabatier, Avenue Georges Pompidou, 81104 Castres, France
}

G R A P H I C A L A B S T R A C T

Keywords:

Calcium hydroxyapatite

Characterization

One-step synthesis

Kinetic sorption

Mechanism
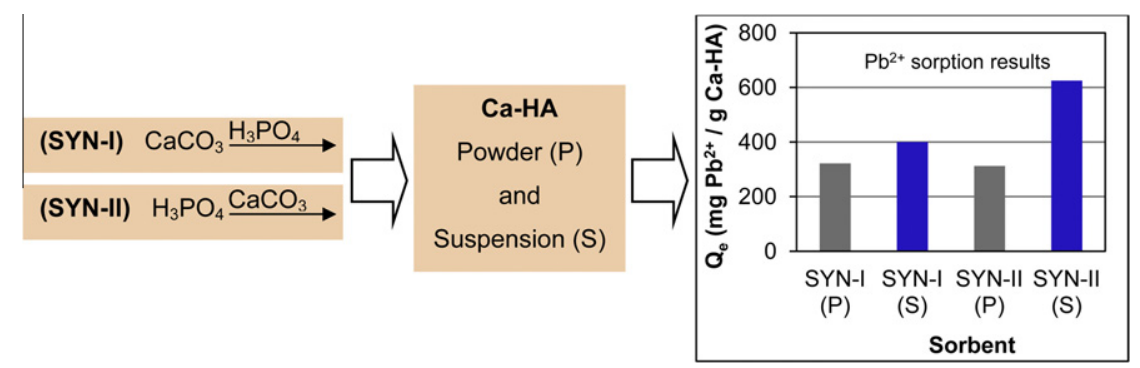

\section{A B S T R A C T}

The synthesis of calcium hydroxyapatite (Ca-HA, chemical formula $\left.\mathrm{Ca}_{10}\left(\mathrm{PO}_{4}\right)_{6}(\mathrm{OH})_{2}\right)$ from calcium carbonate and orthophosphoric acid was investigated under atmospheric conditions to determine their suitability as economical starting materials. The order in which reactants were added influenced only the particle size distribution of the solid products. Calcium carbonate particles were rapidly dissolved in acid medium of orthophosphoric acid. The divalent calcium formed was then precipitated with orthophosphate species to form small primary calcium phosphate particles $(<1 \mu \mathrm{m})$ which partially agglomerated into larger particles with a particle size of up to $300 \mu \mathrm{m}$. The dissolution of calcium carbonate was not complete, even after a long reaction time of $72 \mathrm{~h}$ and large particles with core-shell structures were formed from residual calcium carbonate particles (core) and calcium phosphate based compounds (shell). Using different characterization techniques, the principal intermediates of the reaction could be identified including mono-calciumphosphate monohydrate ( $\left.\mathrm{MCPM}, \mathrm{Ca}\left(\mathrm{H}_{2} \mathrm{PO}_{4}\right)_{2} \cdot \mathrm{H}_{2} \mathrm{O}\right)$, dicalcium phosphate dihydrate (DCPD, $\mathrm{CaHPO}_{4} \cdot 2 \mathrm{H}_{2} \mathrm{O}$ ), dicalcium phosphate anhydrous (DCPAs) and octacalcium bis(hydrogenphosphate) tetrakis(phosphate) pentahydrate (OCP, $\left.\mathrm{Ca}_{8}\left(\mathrm{HPO}_{4}\right)_{2}\left(\mathrm{PO}_{4}\right)_{4} \cdot 5 \mathrm{H}_{2} \mathrm{O}\right)$. Their evolution during the synthesis was followed. The final products obtained after $72 \mathrm{~h}$ of synthesis contained a mixture of Ca-HA, OCP, B-type calcium carbonate-apatite (CAP, $\left.\mathrm{Ca}_{10}\left(\mathrm{PO}_{4}\right)_{6} \mathrm{CO}_{3}\right)$ with low crystallinity and some small amounts of intermediates. The removal of $\mathrm{Pb}^{2+}$ ions, used as a model pollutant, was performed with the calcium phosphate sorbents in powder form or in suspension form. The highest sorption capacity was found at $625 \mathrm{mg} \mathrm{g}^{-1}$ for the sorbent in suspension form which resulted from the addition of calcium carbonate powder to the solution of orthophosphoric acid. From the identification of the composition of the sorbents, the reaction pathway for the removal of lead(II) is proposed.

\footnotetext{
* Corresponding author. Tel.: +33 563493258; fax: +33 563493043 .

E-mail address: doan.phamminh@mines-albi.fr (D. Pham Minh).
} 


\section{Introduction}

Ca-HA belongs to the family of apatites including different compounds with similar structures. Much work has been done on the synthesis of Ca-HA because of its many potential applications in different fields such as medicine [1], gas sensors [2], material for chromatography column [3-5], heterogeneous catalysis [6,7], the removal of heavy metals from contaminated soils, or in the treatment of wastewater and fly ashes [8,9]. In general, Ca-HA preparation consists of the reaction between a calcium source and an orthophosphate source under basic $\mathrm{pH}$ conditions (atmospheric or hydrothermal conditions). The most common starting materials are calcium nitrate and calcium chloride as calcium sources, and alkali or ammonium orthophosphate salts as orthophosphate sources because of their high solubility in aqueous solutions [1012]. Using calcium nitrate and ammonium dihydrogen orthophosphate, Verwilghen et al. were successful in preparing high specific surface area Ca-HA which was relatively stable over a long aging time of up to 21 months [13]. A collagen/nano-Ca-HA scaffold was synthesized using bovine achilles tendon collagen type I as a template, calcium chloride and orthophosphoric acid/sodium hydroxide mixture where prism needle-like nano-HA crystallites precipitated on collagen fibrils [14]. However, a common feature of the use of water soluble calcium and orthophosphate salts is the need for a washing step, which could be arduous when nanometric particles are formed. In addition, this pathway results in the non-used ions such as $\mathrm{NO}_{3}^{-}, \mathrm{Cl}^{-}, \mathrm{NH}_{4}^{+}, \mathrm{K}^{+}$, and $\mathrm{Na}^{+}$, being wasted. The synthesis of $\mathrm{Ca}-\mathrm{HA}$ using calcium carbonate and orthophosphoric acid is of strategic value, because of the low cost and high availability of these materials in comparison with water soluble calcium and orthophosphate salts. Although work has already been initiated with calcium carbonate and orthophosphoric acid, calcium carbonate has usually been converted into active lime or calcium hydroxide forms by thermal decomposition, a step which increases the manufacturing cost $[15,16]$.

The present study aims to investigate the direct synthesis of CaHA from calcium carbonate powder and orthophosphoric acid at ambient conditions and the reactivity of the resulting products in the sorption of concentrated aqueous lead nitrate solution.

\section{Materials and methods}

Ca-HA synthesis was carried out in a $2.3 \mathrm{~L}$ glass $\mathrm{U}$-form reactor (i.d: $10 \mathrm{~cm}$, length: $30 \mathrm{~cm}$ ) with a vertical stainless steel stirrer. Calcium carbonate powder (98\%, Fisher Scientific), orthophosphoric acid (85\% wt in water, Merck) and lead nitrate (99\%, Fisher Scientific) were used as received. Two protocols were used for the synthesis of Ca-HA by changing the addition order of reactants. In the first synthesis (SYN-I), $800 \mathrm{~mL}$ of water and $2 \mathrm{~mol}$ of calcium carbonate were introduced in the reactor under stirring (400 rpm). When the $\mathrm{pH}$ of the suspension was stable, $1.2 \mathrm{~mol}$ of orthophosphoric acid (volume $80 \mathrm{~mL}$ ) were added into the calcium carbonate suspension at the rate of $2 \mathrm{~mL} \mathrm{~min}^{-1}$. In the second synthesis (SYN-II), $1.2 \mathrm{~mol}$ of orthophosphoric acid and $800 \mathrm{~mL}$ of water were introduced in the reactor under stirring. Then $2 \mathrm{~mol}$ of calcium carbonate ( $200 \mathrm{~g}$ ) were added to the orthophosphoric acid solution at the rate of $5 \mathrm{~g} \mathrm{~min}^{-1}$. The addition time of the reactants was $40 \mathrm{~min}$ in both syntheses. The reaction was kept at ambient conditions $\left(\mathrm{ca} .22^{\circ} \mathrm{C}\right.$ ) for $72 \mathrm{~h}$. During the reaction, the $\mathrm{pH}$ of the suspension was measured continuously with a Mettler Toledo MPC pH-meter and recorded using the LabView software. Samples withdrawn from the reaction mixture were filtered on a $0.45 \mu \mathrm{m}$ filter paper to separate liquid and solid phases. The solid was washed several times with permuted water and dried overnight at $105^{\circ} \mathrm{C}$. The liquid phase was acidified with nitric acid to avoid all secondary precipitation from calcium cations and orthophosphate species present in the liquid phase.

X-ray diffraction (XRD) analysis was carried out on a Phillips Panalytical X'pert Pro MPD diffractometer. Simultaneous thermogravimetry and differential scanning calorimetry (TGA-DSC) analysis was carried out in a TA Instruments SDTQ600 analyzer using an air flow rate at $100 \mathrm{~mL} \mathrm{~min}^{-1}$ and a heating rate of $5^{\circ} \mathrm{C} \mathrm{min}-1$ from ambient to $1000^{\circ} \mathrm{C}$. The calcium carbonate contents were calculated according to the corresponding weight loss observed at $700{ }^{\circ} \mathrm{C}$. The particle size distribution was measured by laser scattering in a Mastersizer 2000 instrument in the range from $0.020 \mu \mathrm{m}$ to $2000 \mu \mathrm{m}$. The specific surface area was measured by nitrogen adsorption on a MICROMETRICS Gemini Vacprep 061 using the BET method. SEM-EDX measurement was performed on a Philips XL30 ESEM apparatus. Total inorganic carbon was measured using a Shimadzu TOC- $\mathrm{V}_{\mathrm{CHS}}$ analyzer. The elemental analysis of phosphorus and calcium in the liquid phase was carried out with inductively coupled plasma atomic emission spectroscopy (ICP-AES) on a HORIBA Jobin Yvon Ultima 2.

An aqueous solution containing $6000 \mathrm{mg} \mathrm{L}^{-1}$ of $\mathrm{Pb}^{2+}$ ions was prepared from lead nitrate and permuted water. This concentration was chosen for kinetic sorption study. For the lead removal experiment, $2.4 \mathrm{~g}$ of Ca-HA powder was introduced in a $0.7 \mathrm{~L}$ stirred glass reactor containing $350 \mathrm{~mL}$ of the prepared lead nitrate solution. The experiment was carried out at the stirring speed of $350 \mathrm{rpm}$ and at ambient temperature, ca. $22{ }^{\circ} \mathrm{C}$. The $\mathrm{pH}$ of the solution was continuously measured throughout the experiment. The concentrations of lead, calcium and phosphorus in solution during the run were determined using the ICP-AES technique. The same procedure was applied to the suspension of Ca-HA obtained after $72 \mathrm{~h}$ of synthesis without filtration and drying steps. In this case, the quantity of the suspension was calculated to reach the same equivalent weight of dried matter $(2.4 \mathrm{~g})$.

\section{Results and discussions}

\subsection{TGA-DSC analysis and determination of the intermediates of the reaction}

Fig. 1 presents the TGA-DSC results obtained with the solid products withdrawn at different reaction times.

The number and position of peaks in the derivative thermogravimetry (DTG) curves were relatively similar in both syntheses. The first weight loss at temperature lower than $100^{\circ} \mathrm{C}$ was due to the removal of physically adsorbed surface moisture. The second weight loss at $110^{\circ} \mathrm{C}$, with higher intensity, was due to the dehydration of mono-calciumphosphate monohydrate (MCPM, $\mathrm{Ca}\left(\mathrm{H}_{2-}\right.$ $\left.\mathrm{PO}_{4}\right)_{2} \cdot \mathrm{H}_{2} \mathrm{O}$ ) which was the principal product described in the synthesis from calcium carbonate and orthophosphoric acid in water-acetone solvent [17]. MCPM was still present in the final product after $72 \mathrm{~h}$ of reaction and its multi-step thermal decomposition could also be the origin of the weak peak at $250{ }^{\circ} \mathrm{C}$. The net peak at $190^{\circ} \mathrm{C}$ corresponded to the dehydration of dicalcium phosphate dihydrate (DCPD, $\mathrm{CaHPO}_{4} \cdot 2 \mathrm{H}_{2} \mathrm{O}$ ) which was another major intermediate in Ca-HA synthesis [18-20]. DCPD was also present in the final product of SYN-II but had almost disappeared in the final product of SYN-I. The weight loss at $415^{\circ} \mathrm{C}$ was attributed to the condensation of dicalcium phosphate anhydrous (DCPAs) which was formed from the dehydration of DCPD but could also be present in the solid products as an intermediate [21]. The major weight loss at $705^{\circ} \mathrm{C}$ corresponded to the decomposition of the calcium carbonate remaining in the solid products. Finally, a small weight loss was recorded at about $790^{\circ} \mathrm{C}$ in the solids obtained at the end of reaction ( $48 \mathrm{~h}$ or $72 \mathrm{~h}$ of reaction) which could be due to the decarbonation of carbonate apatite (type B) [22]. The latter 

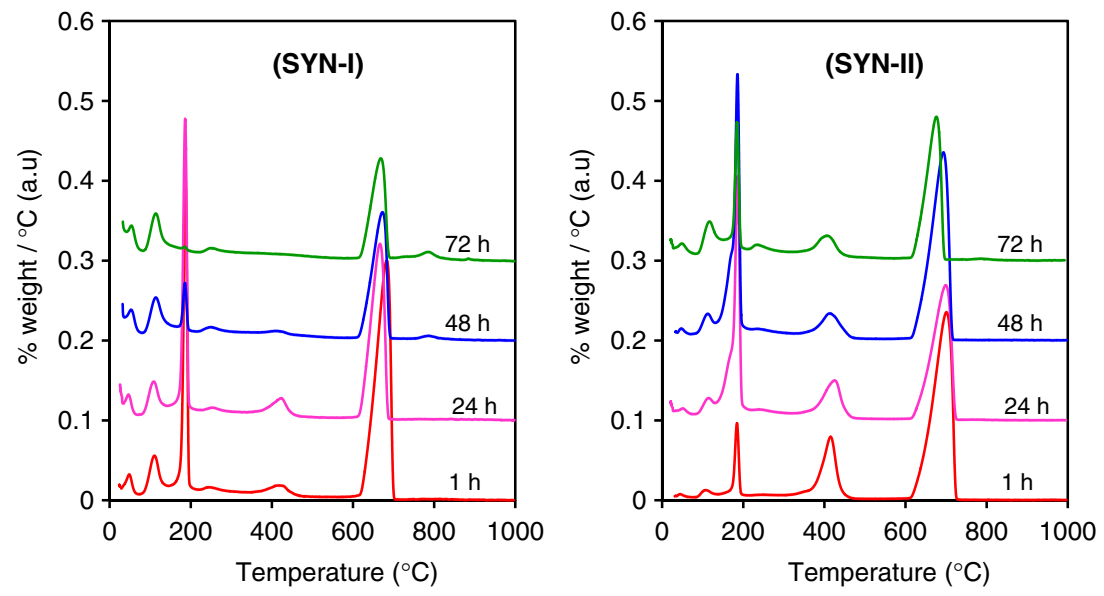

Fig. 1. DTG curves (arbitrary unit) in TGA-DSC analysis of solid products.

could be formed when Ca-HA crystal growth has taken place in the presence of carbonate anions or carbonic gas [23,24]. Suchanek et al. attributed the weight loss in the temperature range ca. $570-950{ }^{\circ} \mathrm{C}$ to the decarbonation of carbonate apatite based products issued from the synthesis under similar conditions [25].

All weight losses mentioned above were endothermic. The corresponding DSC curves are not shown in this study.

\subsection{Calcium carbonate and orthophosphoric acid conversion}

From the TG curves, we could calculate the calcium carbonate content in the solid products corresponding to its thermal decomposition at $705^{\circ} \mathrm{C}$ (Fig. 2).

In the synthesis of Ca-HA using calcium carbonate as a calcium source, the dissolution of calcium carbonate is an important parameter to consider. In contact with orthophosphoric acid, calcium carbonate dissolved violently to liberate the carbonic gas during the first few minutes of reaction when the $\mathrm{pH}$ of the suspension was sufficiently acidic. With the increase of the $\mathrm{pH}$, the reaction slowed down. Furthermore, the calcium phosphate precipitates formed by the reaction could limit or prevent the contact between calcium carbonate and soluble orthophosphate species. Thus, a significant dissolution of calcium carbonate occurred in the first hour of reaction, about $72 \%$ in both syntheses. Then the reaction slowed down considerably and despite a long reaction time of $72 \mathrm{~h}$, the conversion of calcium carbonate into calcium phosphates could not exceed the limit of $89 \%$.

The soluble calcium and phosphorus contents in the liquid phase were also analyzed and are illustrated in Fig. 3.

Soluble calcium and phosphorus concentrations were similar in both syntheses. Most initial soluble orthophosphate species could

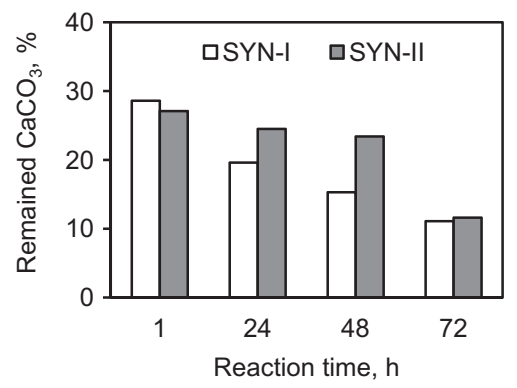

Fig. 2. Calcium carbonate content remaining in the solid product, calculated from TG curves. be totally precipitated during the first reaction period and the concentration of soluble phosphorus stabilized at ca. $1 \mathrm{mM}$. Thus the conversion of soluble orthophosphates into solid calcium phosphates was nearly total. Soluble calcium concentration was higher during the first hour which could be attributed to the presence of calcium phosphates of higher solubility such as MCPM and DCPD. Then its concentration decreased following the transformation of these compounds as confirmed by the ATG-DSC analysis. In fact, soluble calcium and orthophosphate species in the suspension were controlled by the liquid-solid equilibriums of acidic calcium phosphate precipitates formed during the synthesis. Similar results were also found by Kim et al. in the synthesis of Ca-HA starting from calcium hydroxide and orthophosphoric acid [19]. These results indicate that the washing step might be omitted to obtain solid Ca-HA material.

\section{3. $X R D$ characterization}

The solid powders obtained during the course of the syntheses were analyzed by XRD (Fig. 4).

As expected, crystalline calcium carbonate remained at all reaction times. DCPD and DCPA with the $\mathrm{Ca} / \mathrm{P}$ molar ratio of $1 / 1$ were found as the two principal crystalline intermediates after $1 \mathrm{~h}$ of the reaction. These intermediates were nearly totally transformed into apatite phase products after $72 \mathrm{~h}$ of reaction. Three apatites could be identified in the final product $(72 \mathrm{~h})$ which were all of low crystallinity. Ca-HA appeared as the principal apatite, while some amounts of octacalcium bis(hydrogenphosphate) tetrakis(phosphate) pentahydrate (OCP, $\left.\mathrm{Ca}_{8}\left(\mathrm{HPO}_{4}\right)_{2}\left(\mathrm{PO}_{4}\right)_{4} \cdot 5 \mathrm{H}_{2} \mathrm{O}\right)$ and B-type calcium carbonate-apatite (CAP) were also observed. The presence of B-type calcium carbonate-apatite was checked by infra-red analysis with the presence of weak bimodal peak at $1450 \mathrm{~cm}^{-1}$ and $1415 \mathrm{~cm}^{-1}$ (results not shown) [26]. In fact, ambient temperatures did not allow the formation of well crystallized Ca-HA, as observed previously [27]. The OCP was formed because the remaining unreacted calcium carbonate at the end of reaction (about $11 \%$, Fig. 2) led to calcium deficiency form stoichiometric Ca-HA. In fact, the hydrolysis of DCPD - a major intermediate in this synthesis - resulted in the formation of OCP, considered as a precursor of Ca-HA [21]. In addition, the final $\mathrm{pH}$ of the suspension was at about 6.8 , a value favorable for the stability of OCP. As regards the formation of CAP, the carbonic gas formed during the acid attack on calcium carbonate produced bicarbonate and carbonate anions in solution responsible for the formation of carbonate substituted Ca-HA $[23,24,28]$. The presence of CAP was in agreement with the results of TG analysis mentioned above. 

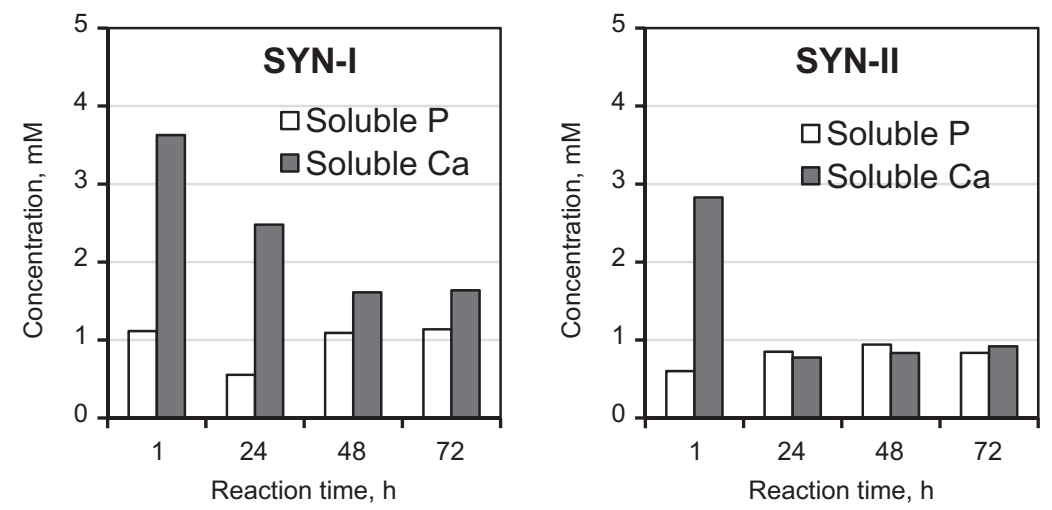

Fig. 3. Soluble calcium and phosphorus in the liquid phase determined by ICP-AES analysis.
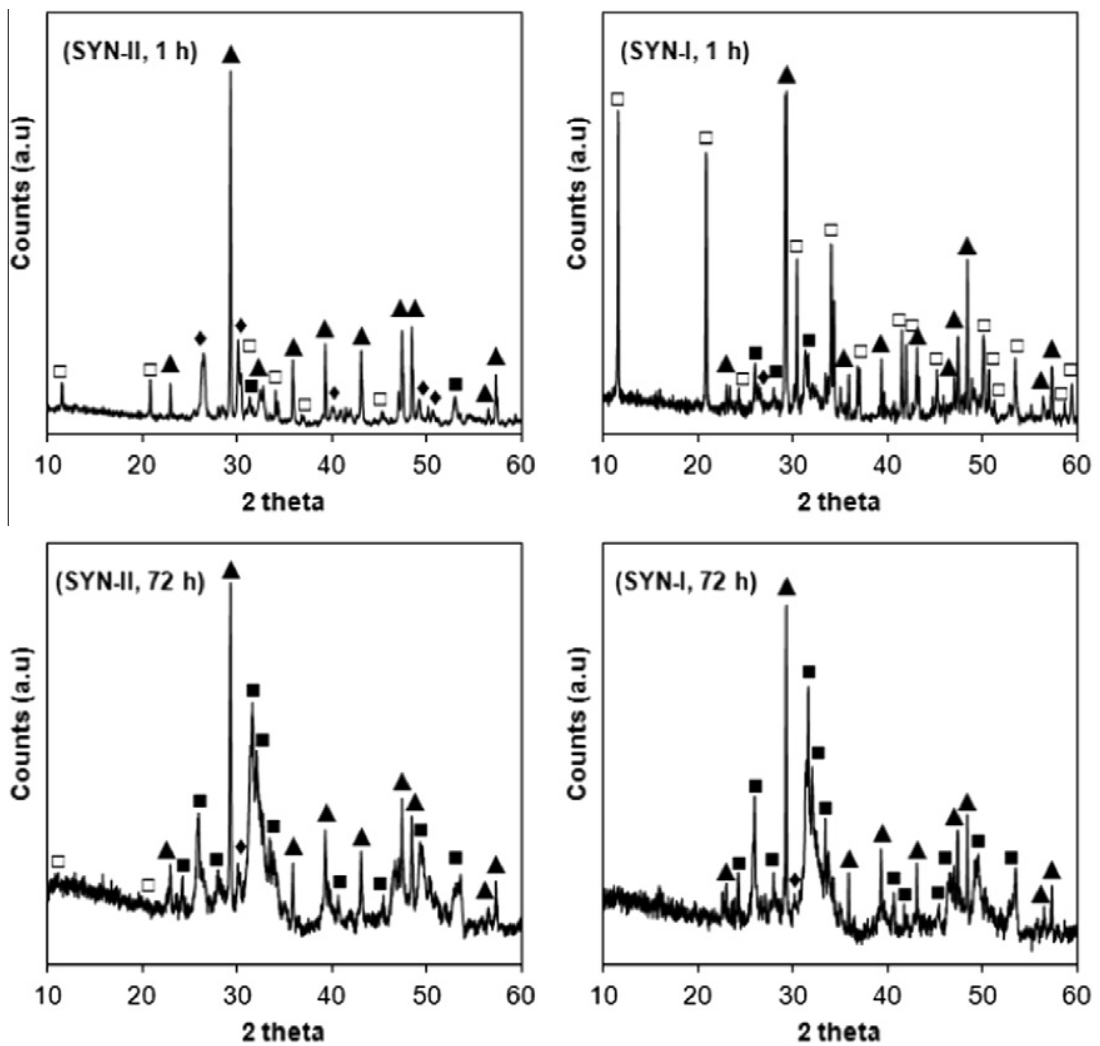

Fig. 4. XRD patterns of the solid powders at $1 \mathrm{~h}$ and $72 \mathrm{~h}$ of reaction; Principal diffractions of calcium carbonate ( $\mathbf{\Delta})$; DCPD ( $\square$ ); DCPA ( $\bullet$ ); apatite structure ( $\mathbf{\square})$.

To verify the presence of CAP in the solid products, a comparison of inorganic carbon contents analyzed by TG and TOC analyzer is shown in Table 1 . In all cases, the total inorganic carbon content determined by the TOC analyzer was slightly higher than the inorganic carbon content in calcium carbonate form derived from TG curves. Therefore CAP was well formed under the reaction conditions used.

\subsection{Particle size distribution}

To better understand the formation of solid particles during the reaction, the particle size distribution of the initial calcium carbonate and of the solid products obtained at $72 \mathrm{~h}$ of reaction was investigated. Both particle number (left) and particle volume (right) data are presented (Fig. 5).
Initial calcium carbonate had narrow particle size distributions of the Gaussian-like type which were in the range from $5 \mu \mathrm{m}$ to $70 \mu \mathrm{m}$. Both final solid products had similar particle number distributions (left-hand side) with $90 \%$ of particles having a size smaller

Table 1

Analysis of inorganic carbon in the solid products; $\mathrm{IC}^{\text {Total }}$ - total inorganic carbon by TOC analyzer; $\mathrm{IC}^{\mathrm{TGA}}$ - inorganic carbon in $\mathrm{CaCO}_{3}$ form by TG curves.

\begin{tabular}{llllll}
\hline \multirow{2}{*}{ Reaction time $(\mathrm{h})$} & \multicolumn{2}{l}{ SYN-I } & & \multicolumn{2}{l}{ SYN-II } \\
\cline { 2 - 3 } \cline { 5 - 6 } & $\mathrm{IC}^{\text {Total }}$ & $\mathrm{IC}^{\mathrm{TGA}}$ & & $\mathrm{IC}^{\text {Total }}$ & $\mathrm{IC}^{\mathrm{TGA}}$ \\
\hline 1 & 34.4 & 34.3 & 32.7 & 32.5 \\
24 & 25.1 & 23.5 & 29.7 & 29.4 \\
48 & 19.6 & 19.3 & 28.1 & 28.1 \\
72 & 13.6 & 13.3 & 15.3 & 13.9 \\
\hline
\end{tabular}

Unit: mg of carbon per $\mathrm{g}$ of solid. 

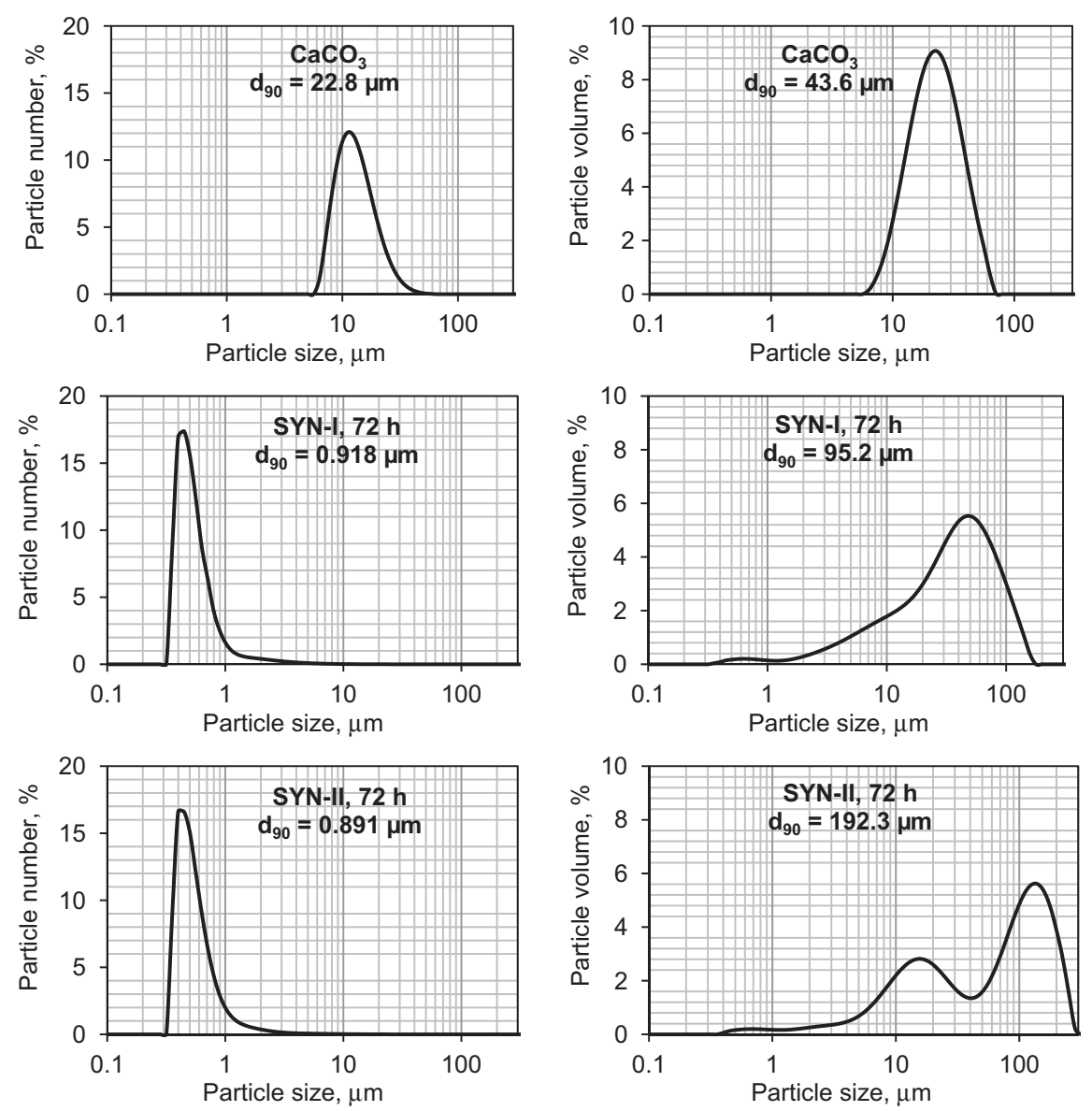

Fig. 5. Percentage by number (left) and volume (right) as a function of particle size of initial calcium carbonate and final solid products obtained at $72 \mathrm{~h}$ of reaction; particle size is in logarithm base 10 scale.
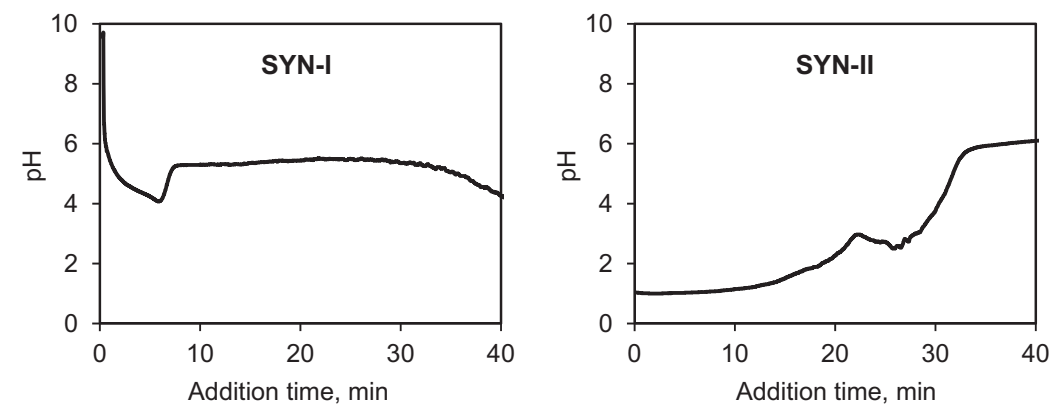

Fig. 6. $\mathrm{pH}$ change during the addition time of reactants ( $40 \mathrm{~min}$ in both syntheses); SYN-I: all calcium carbonate particles underwent the same pH attack when orthophosphoric acid was continuously added to calcium carbonate suspension; SYN-II: the acid attack was not the same when calcium carbonate was progressively added to orthophosphoric acid solution.

than $0.918 \mu \mathrm{m}\left(d_{90}\right)$. The number of particles larger than $4 \mu \mathrm{m}$ was negligible. On the particle volume distributions of final products (right-hand side), bimodal and trimodal peaks appeared in the final products of SYN-I and SYN-II, respectively. In SYN-I, two groups of particles in the range of approximately $0.3-1.5 \mu \mathrm{m}$ and $2-300 \mu \mathrm{m}$ could be distinguished. In SYN-II three groups of particles could be observed including $0.3-1.5 \mu \mathrm{m}, 4-12 \mu \mathrm{m}$ and $12-300 \mu \mathrm{m}$ groups. The formation of these groups of particle sizes can be explained by the order of addition of the reactants and by the agglomeration phenomenon of primary particles. Thus, during the first minutes of reaction, calcium carbonate was strongly dissolved by orthophosphoric acid. Calcium cations $\left(\mathrm{Ca}^{2+}\right)$ formed by this acid attack were then precipitated with orthophosphate anions leading to the formation of small particles (particle sizes less than $1 \mu \mathrm{m}$ ) as shown in the particle number distributions. These small particles are considered as primary particles which partially agglomerate into larger particles. Some of the initial calcium carbonate particles were not totally dissolved and wrapped in calcium phosphate shells, making larger particles of the core-shell type. In SYN-I, as orthophosphoric acid was continuously added to the suspension of calcium carbonate, all of it underwent the same acid attack during the reaction resulting in the formation of regular primary particles. Thus two particle populations including primary particles and their agglomerates and core-shell structure particles 

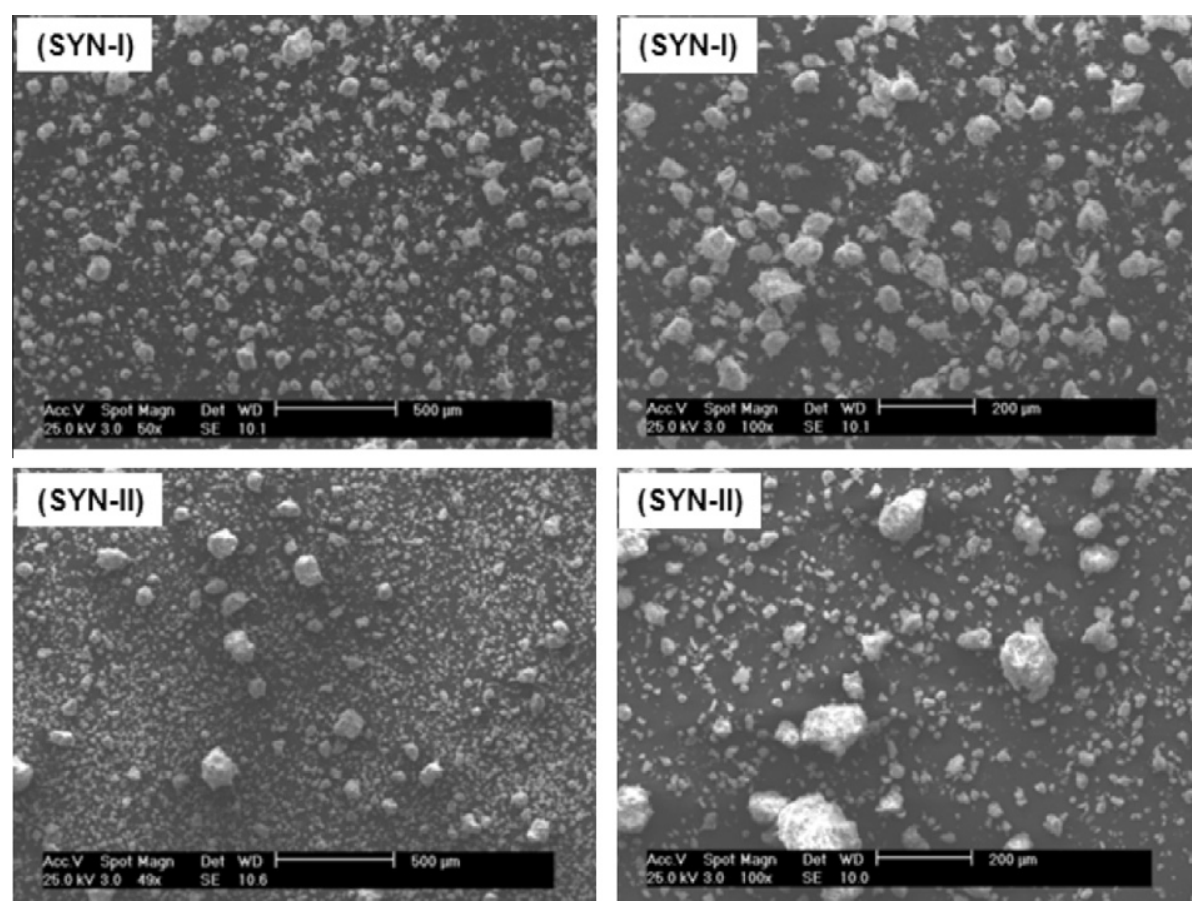

Fig. 7. SEM images of the final solid powders after $72 \mathrm{~h}$ of reaction.

were formed yielding a bimodal particle volume distribution. In SYN-II, calcium carbonate powder was progressively added to the solution of orthophosphoric acid. The acid attack on the calcium carbonate particles was not the same during the course of this addition, because of the rapid dissolution from $\mathrm{pH}$ values of 1 at the beginning to slow reaction near $\mathrm{pH} 6$ at the end of the calcium carbonate addition (Fig. 6). Thus, calcium phosphate particles formed during this synthesis were irregular and gave a trimodal distribution of the particles.

\subsection{SEM-EDX analysis}

Textural and morphological properties and elemental qualitative analysis of the final solid powders were studied using SEM to further investigate the particle size differences. Fig. 7 illustrates the general observation of particle sizes which changed in wide range for both products. In SYN-I, no particles with sizes larger than $200 \mu \mathrm{m}$ were observed. On the other hand, particles with sizes up to $300 \mu \mathrm{m}$ were found in SYN-II, in agreement with the results in Fig. 5.

To better understand the morphology, formation and composition of the large particles, the initial external surface (Fig. 8A) and the interior of fractured particles were directly observed at higher magnification (Fig. 8B and C).

Fig. 8A illustrates the external surface of a large particle composed of several primary particles, mainly of plate-like morphology. This type is characteristic of DCPD particles [29]. This observation confirmed the formation of large particles by agglomeration of primary particles. EDX analysis of the surface of these particles showed the usual Ca/P molar ratio close to $1 / 1$ of DCPD.

Fig. $8 \mathrm{~B}$ and $\mathrm{C}$ shows images obtained from the inside of the particles resulting from sharp splitting with sterile surgical blades $\left(\mathrm{N}^{\circ}\right.$ 11, Alframed, France). Fig. $8 \mathrm{~B}$ illustrates the cut surface of a big particle formed from agglomeration of primary particles. EDX analysis on this cut surface showed in all cases the presence of calcium phosphate based products with a $\mathrm{Ca} / \mathrm{P}$ molar ratio higher than $1 /$ 1 in most cases. Fig. $8 \mathrm{C}$ shows the cut surface of a core-shell type particle in which calcium carbonate was found in the core (in the interior of the black ellipse) and calcium phosphate based products were found in the shell (in the exterior of the black ellipse), as shown in Fig. 8D and E. At higher enlargement ( $2 \mu \mathrm{m}$ scale), the boundary between the core and shell of the particle could be observed (Fig. 8C, hand-right). Thus large particles could be formed by the agglomeration of primary particles (Fig. 8B) or by the direct growth of calcium phosphates on the surface of remaining calcium carbonate (Fig. 8C). These large particles were found for both SYN-I and SYN-II powders.

\subsection{Reactivity in the removal of lead(II) in aqueous solutions}

The final products of our syntheses in powder and suspension forms were tested for the removal of dissolved lead(II) ions. The usual Ca-HA synthetic procedure includes a filtration, washing and drying step for the elimination of residual ions from initial reactants such as nitrate, chloride, potassium, ammonium, sodium. This results in the formation of Ca-HA as a powder. Thus the removal of heavy metals is usually performed with the solid powder. However, in the present study, there were no residual counter-ions remaining from calcium carbonate and orthophosphoric acid as initial reactants. Soluble calcium and phosphorus contents in the liquid phase were very low, as shown in Fig. 3. Thus it was interesting to compare the reactivity of the as-synthesized products in fresh suspension form (named SYN-I suspension or SYN-II suspension) and the powder form (named SYN-I powder or SYN-II powder) for the removal of lead(II) as a model pollutant.

Fig. 9 presents the influence of contact time on the evolutions of removed lead(II) and released calcium(II) for the sorbents in powder form ( $A$ and $B$ ) or fresh suspension form (C and D). The initial lead nitrate aqueous solution was prepared at $6000 \mathrm{mg} \mathrm{L}^{-1}$ or $28.95 \mathrm{mmol} \mathrm{L}^{-1} \mathrm{~Pb}^{2+}$ which had the initial acid pH of 5.1 at ambient temperature. The removal of lead(II) took place in two separated steps as observed in previous studies [30,31]. The first step was rapid and quantitatively significant, due to the initial abundance of active sites on the surface of the sorbents. The second step 
(A)

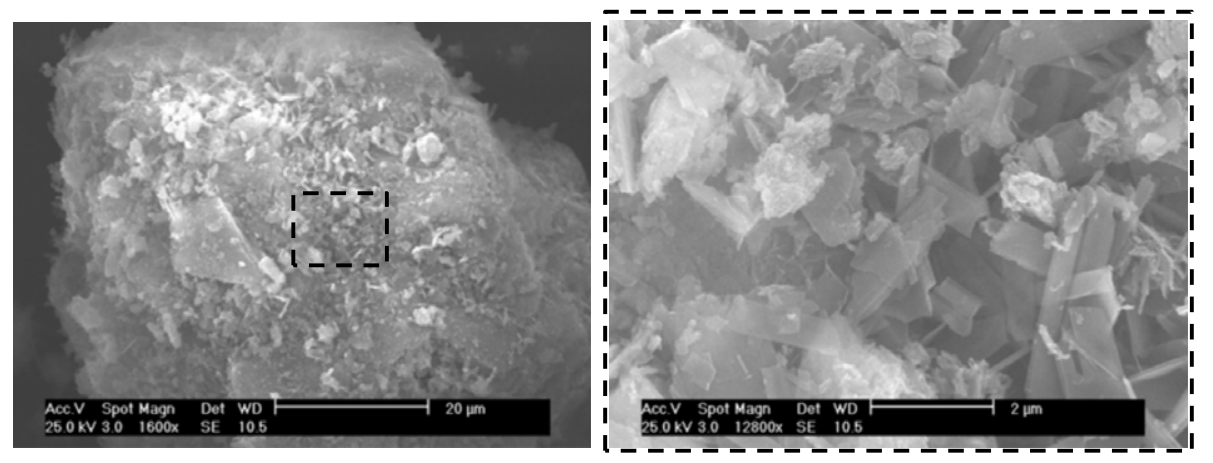

(B)

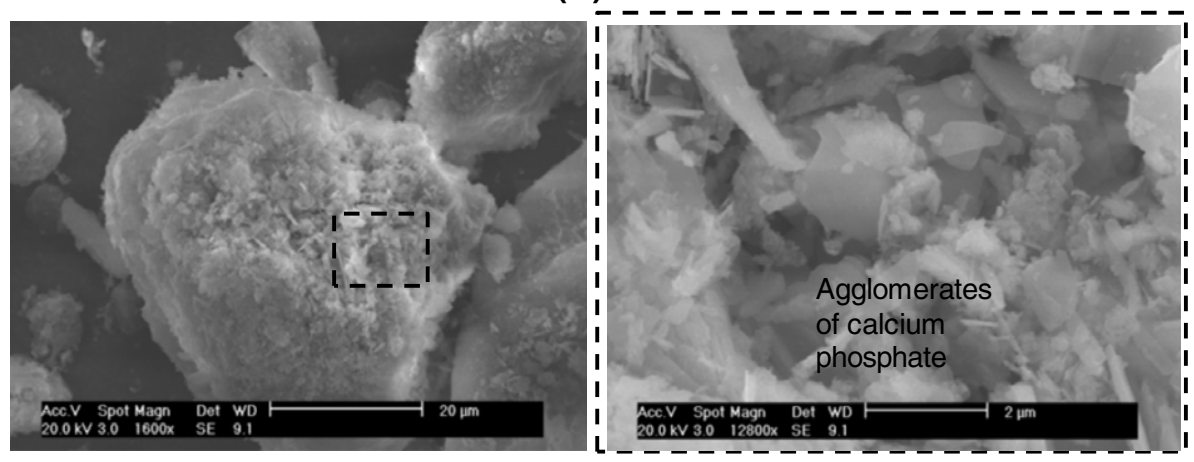

(C)
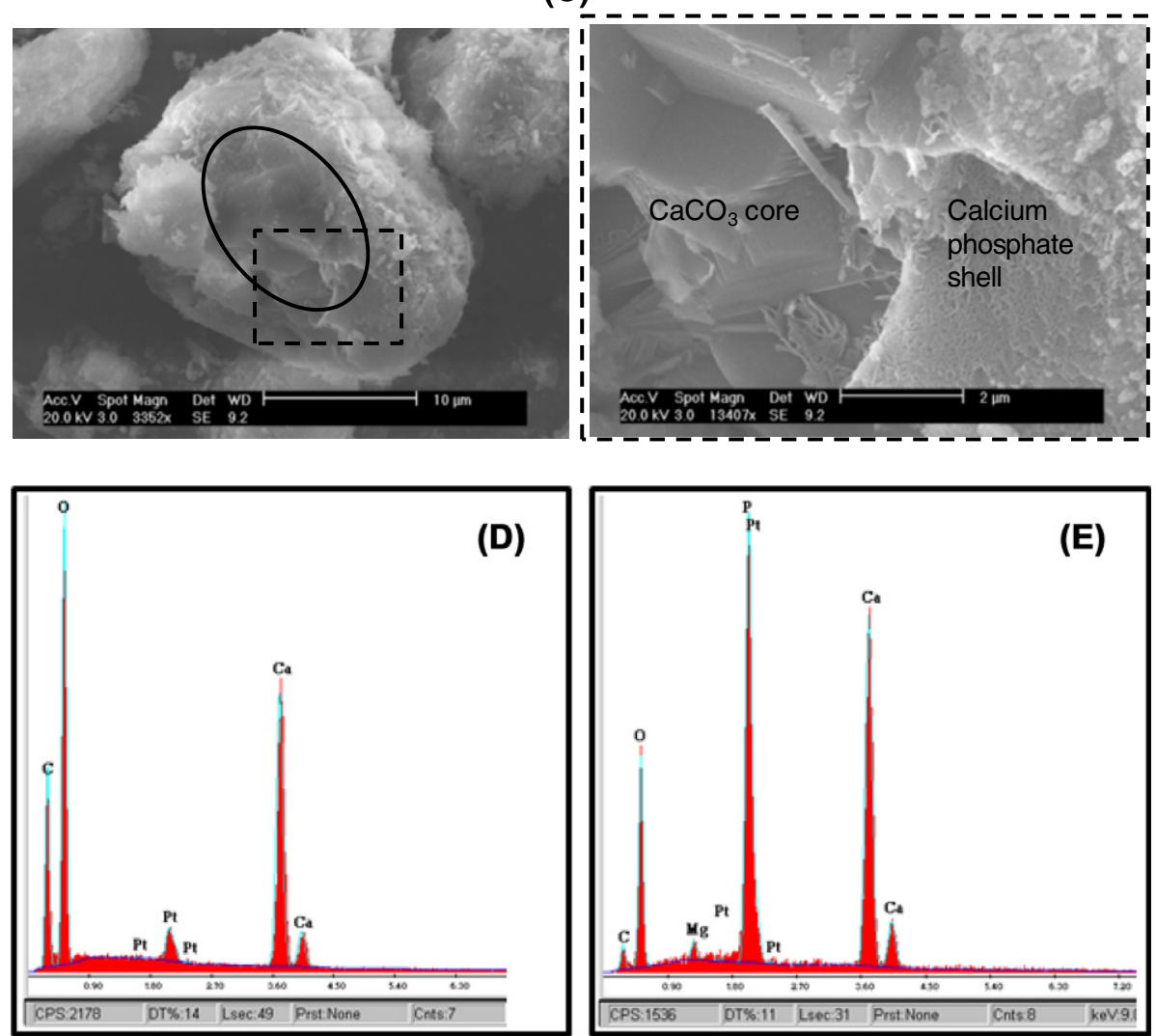

Fig. 8. SEM images of big particles; (A): observation on initial external surface; (B and C): observation on cut surface; (D and E): examples of EDX analysis of core and shell cut surface, respectively.

was slower and quantitatively less significant. Both SYN-I and SYNII powders having the same specific surface area of $44 \mathrm{~m}^{2} \mathrm{~g}^{-1}$ and particle number distribution possessed similar reactivity for the removal of lead(II) with ca. $35 \%$ of lead(II) elimination after $5 \mathrm{~h}$ of contact time, after which the sorption rate considerably decreased. Both SYN-I and SYN-II suspensions were found to be much more 

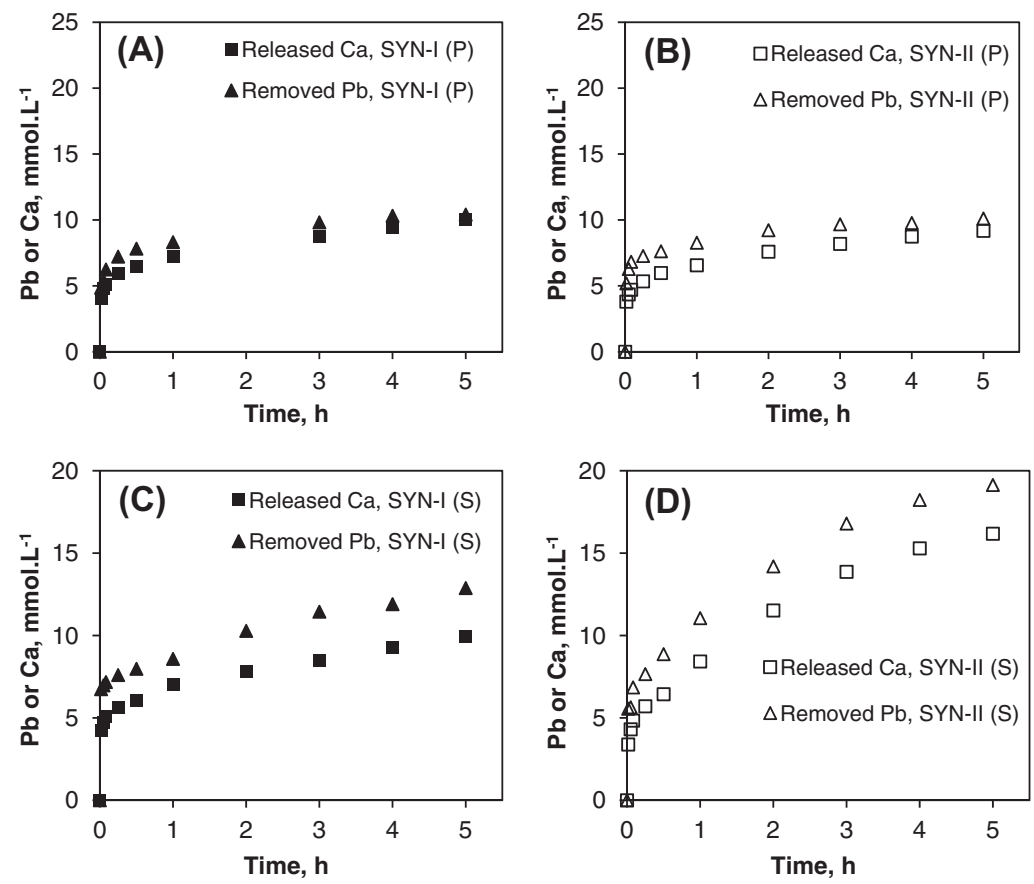

Fig. 9. Evolution of $\mathrm{Pb}^{2+}$ removal and $\mathrm{Ca}^{2+}$ release in batch sorption kinetic measurements using SYN-I and SYN-II powders (A and B) and SYN-I and SYN-II suspensions ( $\mathrm{C}$ and D); (P): powder and (S): suspension.

active than SYN-I and SYN-II powders produced by the same synthesis. The extent of lead(II) removal was $44.6 \%$ for SYN-I suspension (Fig. 9C) and 66.0\% for SYN-II suspension (Fig. 9D) after $5 \mathrm{~h}$ of contact time where the sorption continued. The higher reactivity of SYN-I and SYN-II suspensions cannot be due to the presence of soluble orthophosphate species in the liquid phase, given their very low concentrations. In fact, from the concentration of soluble phosphorus in liquid phase (Fig. 3) and the volume of fresh suspension used in sorption experiments (ca. $10 \mathrm{~mL}$ ), the total quantity of soluble orthophosphate species could be calculated as not exceeding $0.009 \mathrm{mmol}$ and was much smaller than the quantity of removed lead(II). Probably the overnight drying step at $105^{\circ} \mathrm{C}$ had some effects on the physico-chemical properties of the materials, such as the specific surface area, size, porosity or the presence of functional groups at the surface of particles. Further characterizations of the suspension should help to better understand their reactivity in the sorption process.

In order to investigate the rate of lead(II) removal, the data in Fig. 9 were analyzed using a pseudo-second order equation [32]. This equation was developed for the kinetic sorption over a long contact time and was found to provide very good correlation for

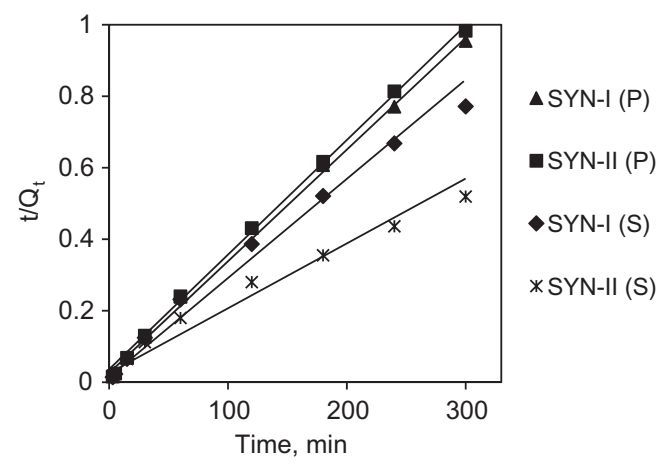

Fig. 10. Pseudo-second order sorption kinetic (Eq. (1)) of $\mathrm{Pb}^{2+}$ onto $\mathrm{Ca}-\mathrm{HA}$ in powder form (P) and fresh suspension form (S). different studied systems such as the sorption of soluble cadmium(II) onto dry reed leaves, copper(II) and lead(II) onto bottom ash, phosphate using both un-rinsed and rinsed tamarind nut shell activated carbon [32]. This equation is described as follows:

$t / Q_{t}=1 / h+t \times 1 / Q_{e}$

where $Q_{t}$ is the amount of soluted sorbate on the surface of the sorbent at any time $t\left(\mathrm{mg} \mathrm{g}^{-1}\right) ; Q_{e}$ is the amount of soluted sorbate sorbed at equilibrium $\left(\mathrm{mg} \mathrm{g}^{-1}\right) ; t$ is the contact time (min); and $h$ is the constant of sorption rate $\left(\mathrm{g} \mathrm{mg}^{-1} \mathrm{~min}^{-1}\right)$.

Fig. 10 illustrates the plots of $t / Q_{t}$ against the contact time $t$. In all cases we obtained linear plots with good coefficients of determination $R^{2}$ (Table 2). The linearity of these plots means that the pseudo-second order kinetic model is followed in the sorption of lead onto the synthesized Ca-HA based materials. Table 2 reports the values of $Q_{e}$ and $h$ obtained from the plots in Fig. 10. SYN-II suspension was the most active for the removal of lead(II) with the derived sorption capacity of $625 \mathrm{mg} \mathrm{g}^{-1}$.

The removal of lead(II) took place simultaneously with the release of calcium(II), as shown in Fig. 9. The molar concentration of released calcium(II) was smaller than the molar concentration of removed lead(II) indicating that the reaction mechanism was not the exactly equimolar exchange which is usually observed for the removal of metals by Ca-HA materials [33]. In fact, the sorbents used in the present study contained a mixture of calcium phosphates including Ca-HA, OCP, CAP, DCPD, DCPA, MCPM and non-dissolved calcium carbonate. The sorption of metals on

Table 2

Sorption capacity $\left(Q_{e}\right)$ and rate constant $(h)$ of synthesized Ca-HA calculated from the pseudo-second order sorption kinetic model; $(\mathrm{P})$ : powder; $(\mathrm{S})$ : suspension.

\begin{tabular}{llll}
\hline Ca-HA used & $Q_{e}\left(\mathrm{mg} \mathrm{g}^{-1}\right)$ & $h\left(\mathrm{~g} \mathrm{mg}^{-1} \mathrm{~min}^{-1}\right)$ & $R^{2}$ \\
\hline SYN-I (P) & 322 & 33 & 0.9984 \\
SYN-II (P) & 312 & 34 & 0.9985 \\
SYN-I (S) & 400 & 21 & 0.9897 \\
SYN-II (S) & 625 & 18 & 0.9821 \\
\hline
\end{tabular}




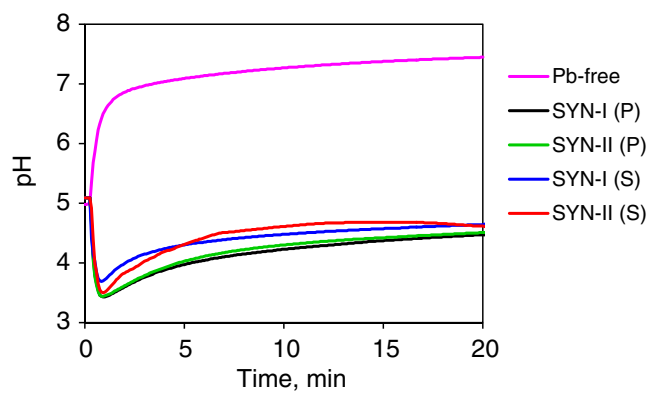

Fig. 11. $\mathrm{pH}$ evolution during the first min of contact time in the removal of lead(II); Pb-free: $\mathrm{pH}$ evolution in Pb-free conditions using SYN-II solid.

Ca-HA sorbents results generally in an equimolar exchange $[30,33,34]$ as given in the following equation:

$\mathrm{Ca}_{10}\left(\mathrm{PO}_{4}\right)_{6}(\mathrm{OH})_{2}+x \mathrm{~Pb}^{2+} \rightarrow \mathrm{Ca}_{10-x} \mathrm{~Pb}_{x}\left(\mathrm{PO}_{4}\right)_{6}(\mathrm{OH})_{2}+x \mathrm{Ca}^{2+}$

In this study, calcium phosphate based products such as OCP, DCPD and DCPA with a Ca/P molar ratio smaller than 1.67 probably participated in the sorption process. As example, a mixture of DCPD and $\mathrm{MgHPO}_{4} \cdot 2 \mathrm{H}_{2} \mathrm{O}$ has been found to be active in the removal of lead(II) [35]. The reaction of lead(II) and these calcium phosphates results in the formation of apatitic products with increased $\mathrm{M} / \mathrm{P}$ molar ratio ( $\mathrm{M}$ is $\mathrm{Pb}$ or $\mathrm{Ca}$ ) which explains the lower concentration of released calcium(II) compared with that of removed lead(II). In the ideal case where lead hydroxyapatite is formed, the following equations may be proposed for OCP, DCPD and DCPA, respectively:

$\mathrm{Ca}_{8}\left(\mathrm{HPO}_{4}\right)_{2}\left(\mathrm{PO}_{4}\right)_{4} \cdot 5 \mathrm{H}_{2} \mathrm{O}+10 \mathrm{~Pb}^{2+} \rightarrow \mathrm{Pb}_{10}\left(\mathrm{PO}_{4}\right)_{6}(\mathrm{OH})_{2}+8 \mathrm{Ca}^{2+}+2 \mathrm{H}^{+}+5 \mathrm{H}_{2} \mathrm{O}$

$6\left[\mathrm{CaHPO}_{4} \cdot 2 \mathrm{H}_{2} \mathrm{O}\right]+10 \mathrm{~Pb}^{2+} \rightarrow \mathrm{Pb}_{10}\left(\mathrm{PO}_{4}\right)_{6}(\mathrm{OH})_{2}+6 \mathrm{Ca}^{2+}+8 \mathrm{H}^{+}+10 \mathrm{H}_{2} \mathrm{O}$

$6 \mathrm{CaHPO}_{4}+2 \mathrm{H}_{2} \mathrm{O}+10 \mathrm{~Pb}^{2+} \rightarrow \mathrm{Pb}_{10}\left(\mathrm{PO}_{4}\right)_{6}(\mathrm{OH})_{2}+6 \mathrm{Ca}^{2+}+8 \mathrm{H}^{+}$

According to these equations, the number of released calcium cations is smaller than the number of removed lead cations in each case and is also accompanied by the release of protons. In fact, we observed a strong decrease in $\mathrm{pH}$ in the first contact time as shown in Fig. 11. Thereafter the $\mathrm{pH}$ increased at a slower rate. Note that in $\mathrm{Pb}$-free conditions, the $\mathrm{pH}$ rapidly increased when SYN-II solid was added to water having the initial $\mathrm{pH}$ adjusted at 5 with $\mathrm{HNO}_{3}$, and no $\mathrm{pH}$ drop was observed in this case (Pb-free curve, Fig. 11). This was also observed for SYN-I solid. Thus, the pH drop in lead(II) sorption was only due to the release of proton according to Eqs. (3)-(5).

The reaction mechanism can be explained as follows: firstly, the reaction of lead(II) with calcium phosphate products having the $\mathrm{Ca} / \mathrm{P}$ molar ratio lower than 1.67 , as given in Eqs. (3)-(5), took place and led to the decrease in the $\mathrm{pH}$. As mentioned above in the SEM-EDX analysis results (Fig. 8), the Ca/P molar ratio at the surface of particles was usually found to be close to $1 / 1$, indicating the availability of calcium phosphate products such as DCPD and DCPA which favored the reactions in Eqs. (4) and (5). According to Eqs. (3)-(5), the pH decreased through the liberation of protons. The surface complexation of lead(II) with the $\equiv \mathrm{POH}$ sites present at the surface of Ca-HA particles could also be responsible for the decrease in the $\mathrm{pH}[30,36]$. The duration of the $\mathrm{pH}$ decrease was short and varied in the range from 1 to 2 min. After this decrease, the $\mathrm{pH}$ increased continuously, due to the dissolution in an acid medium

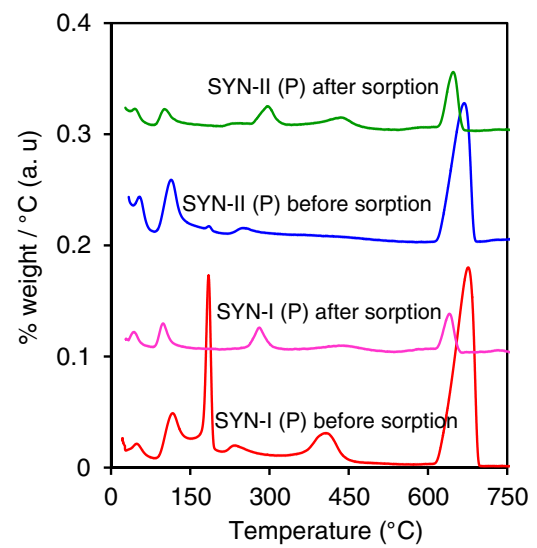

Fig. 12. DTG curves of the sorbents in solid powder form before and after lead(II) sorption process.

of the calcium carbonate remaining in the sorbent. This dissolution occurred with the consumption of protons and therefore the $\mathrm{pH}$ increased moderately. The increase in $\mathrm{pH}$ with the reaction time might also be due to the progressive formation of apatitic compounds which have $\mathrm{pH}_{\mathrm{pzc}}$ higher than that of the DCPD or DCPA located on the surface of particles.

To check the hypothesis of the dissolution of remaining calcium carbonate and the evolution of DCPD and DCPA during the sorption process, the solids recovered after sorption were analyzed by TGADSC (Fig. 12).

As expected, with both SYN-I and SYN-II powders the weight losses due to MCPM $\left(110^{\circ} \mathrm{C}\right), \operatorname{DCPD}\left(190^{\circ} \mathrm{C}\right)$, DCPA $\left(415^{\circ} \mathrm{C}\right)$ and $\mathrm{CaCO}_{3}\left(705^{\circ} \mathrm{C}\right)$ were clearly reduced after lead(II) sorption indicating their consumption during the sorption process. In addition, the solid powders after sorption had a new peak at $280^{\circ} \mathrm{C}$, due to a new product of the reaction between lead(II) and SYN-I and SYNII powders. This study could not be done with SYN-I and SYN-II suspensions because we could not correctly analyze SYN-I and SYN-II suspensions by the TGA-DSC technique.

Taking into account the increase in weight of the solids recovered after sorption which was due to the replacement of calcium(II) by lead(II), the amount of MCPM, DCPD, DCPA and $\mathrm{CaCO}_{3}$ present in the SYN-I and SYN-II powders before and after sorption could be calculated. The results are presented in Table 3. The total quantity of DCPD and DCPA and about half the MCPM were transformed into other calcium phosphates and a large part of residual calcium carbonate was dissolved.

From Eqs. (3)-(5), the gap between released calcium(II) and removed lead(II) concentrations depends on the quantity of OCP, DCPD and DCPA present in the used sorbents. Considering that OCP content in SYN-I and SYN-II was negligible, the gap between released calcium(II) and removed lead(II) concentrations using SYN-I powder (Fig. 9A) was smaller than that using SYN-II powder (Fig. 9B), which can be explained by the higher contents of DCPD and DCPA in SYN-II (Table 3). This gap was much bigger in the cases of SYN-I and SYN-II suspensions, which suggests that OCP,

Table 3

Contents of calcium phosphates with $\mathrm{Ca} / \mathrm{P}$ molar ratio of $0.5-1 / 1$ and residual calcium carbonate in the sorbents before and after the sorption process.

\begin{tabular}{llllr}
\hline Solid & MCPM (\%) & DCPD (\%) & DCPA (\%) & $\mathrm{CaCO}_{3}(\%)$ \\
\hline SYN-I before sorption & 2 & 0.3 & 0 & 11.6 \\
SYN-I after sorption & 0.8 & 0 & 0 & 2.6 \\
SYN-II before sorption & 1.6 & 2.5 & 2.0 & 11.1 \\
SYN-II after sorption & 0.6 & 0 & 0 & 4.3 \\
\hline
\end{tabular}


Table 4

Comparison of the synthesized Ca-HA in this work with other sorbents reported in the literature in the sorption of lead(II) from aqueous solution.

\begin{tabular}{|c|c|c|c|c|c|}
\hline Sorbent & Concentration of sorbent $\left(\mathrm{g} \mathrm{L}^{-1}\right)$ & $\mathrm{Pb}$ precursor & Concentration of lead $\left(\mathrm{mg} \mathrm{L}^{-1}\right)$ & $Q_{e}\left(\mathrm{mg} \mathrm{g}^{-1}\right)$ & Ref. \\
\hline Ca-HA & 6.86 & $\mathrm{~Pb}\left(\mathrm{NO}_{3}\right)_{2}$ & 6000 & $322-625$ & This work \\
\hline Ca-HA & 2.5 & $\mathrm{~Pb}\left(\mathrm{NO}_{3}\right)_{2}$ & $581-1770$ & $\approx 468$ & [36] \\
\hline $\mathrm{Ca}-\mathrm{HA}$ & 10 & $\mathrm{~Pb}\left(\mathrm{NO}_{3}\right)_{2}$ & $1000-8000$ & $330-450$ & [30] \\
\hline Activated carbon & 4 & $\mathrm{~Pb}\left(\mathrm{NO}_{3}\right)_{2}$ & $21-2072$ & 110 & [37] \\
\hline Activated carbon & 1 & Unknown & $10-90$ & $9-66$ & [38] \\
\hline XC-72 carbon & $0.05-0.65$ & $\mathrm{~Pb}\left(\mathrm{NO}_{3}\right)_{2}$ & 60 & 125 & [39] \\
\hline Bio-char & 10 & $\mathrm{~Pb}\left(\mathrm{NO}_{3}\right)_{2}$ & 100 & $<15$ & [40] \\
\hline Resin & 6 & Unknown & 207.2 & $\approx 200$ & [41] \\
\hline Resin & 0.05 & $\mathrm{~Pb}\left(\mathrm{NO}_{3}\right)_{2}$ & $500-1500$ & $\approx 250$ & [42] \\
\hline Sediment & 20 & $\mathrm{~Pb}\left(\mathrm{NO}_{3}\right)_{2}$ & $50-1600$ & $\approx 21$ & [43] \\
\hline Soil & $5-10$ & $\mathrm{~Pb}\left(\mathrm{NO}_{3}\right)_{2}$ & $10-400$ & $0.5-8$ & [44] \\
\hline
\end{tabular}

DCPD and DCPA might be present at higher contents in suspension form than in powder form. A forthcoming study on the quantification of OCP, DCPD and DCPA of SYN-I and SYN-II suspensions should be interesting.

Lead(II) is usually used as a model pollutant for the evaluation of retention capacity of sorbents. It is interesting now to compare the synthesized products with the materials reported in the literature for the removal of lead(II). Some data were shown in Table 4.

Ca-HA based solids synthesized from calcium carbonate in this work had the similar $Q_{e}$ for lead(II) removal in comparison with Ca$\mathrm{HA}$ obtained from soluble calcium salt $\left(\mathrm{Ca}\left(\mathrm{NO}_{3}\right)_{2}\right)[30,36]$. In comparison with the classical sorbents such as activated carbons or ion exchange resins, Ca-HA showed much higher $Q_{e}$. Other sorbents like sediment or soil were also used for the immobilization of lea$\mathrm{d}(\mathrm{II})$ which showed low $Q_{e}$. This demonstrates the interest of the use of $\mathrm{Ca}-\mathrm{HA}$ based materials for the environmental purposes.

\section{Conclusion}

The synthesis of Ca-HA using orthophosphoric acid and calcium carbonate as economical starting materials was investigated under atmospheric conditions. The addition order of reactants (SYN-I: adding orthophosphoric acid in the suspension of calcium carbonate and SYN-II: adding calcium carbonate powder in the solution of orthophosphoric acid) influenced only the particle size distribution of the solid powders obtained. Calcium carbonate particles were first dissolved in acid medium into divalent calcium(II) which was then precipitated by orthophosphate species to form primary calcium phosphate particles smaller than $1 \mu \mathrm{m}$. Because of the increase in the $\mathrm{pH}$, some of the initial calcium carbonate particles were not totally dissolved and formed large particles with a core-shell structure. The agglomeration of primary calcium phosphate particles also led to the formation of larger particles with sizes of up to $300 \mu \mathrm{m}$.

The reaction of calcium carbonate powder and orthophosphates species in aqueous medium was a multi-step process with the formation of different intermediates. MCPM, DCPD and DCPA were found as significant intermediates of the reaction. The final solid products after $72 \mathrm{~h}$ of synthesis contained a mixture of low crystalline apatite compounds including Ca-HA, OCP and CAP, small amounts of intermediates and non-dissolved calcium carbonate. In both syntheses, initial orthophosphate species were nearly totally precipitated and only small quantity of soluble calcium(II) and phosphorus were found in the liquid phase.

For the first time, the synthesized products under both powder and suspension forms were compared in the removal of lead(II) nitrate aqueous solution as a model pollutant. Both powder products originating from SYN-I and SYN-II showed similar sorption reactivity indicating that the addition order for reactants had no influence on the sorption reactivity which reached near-equilibrium after $5 \mathrm{~h}$ of contact time. When the sorbents were directly used in suspension form without the filtration and drying steps, higher sorption capacity was obtained and the sorbents had not reached the sorption equilibrium even after $5 \mathrm{~h}$ of contact time. The lead(II) sorption process involved the classical complexation of lead(II) with the $\equiv \mathrm{POH}$ sites on the surface of $\mathrm{Ca}-\mathrm{HA}$ accompanied by the reaction of lead(II) with the non-apatitic calcium phosphates (MCPM, DCPD, DCPA) or calcium-deficient apatite (OCP), which was responsible for the strong decrease in $\mathrm{pH}$ at the beginning of the sorption and the non-equimolar exchange phenomenon. This first step was rapid, thanks to the availability of active sites on the surface of the sorbents. In the second step, the removal of lead(II) slowed down and was accompanied by the continuous moderate increase in $\mathrm{pH}$ which was due to the dissolution of residual calcium carbonate present in the sorbents and the consumption of intermediates of lower $\mathrm{pH}_{\mathrm{pzc}}$ such as MCPM, DCPD, and DCPA. The suspension issued from the synthesis SYN-II, where calcium carbonate powder was added to the solution of orthophosphoric acid, was the most active in the removal of lead(II), with a sorption capacity of $625 \mathrm{mg} \mathrm{g}^{-1}$. This demonstrates an interesting simple route for the production of Ca-HA based materials from economical starting materials and the use of these materials in the treatment of heavy metals in wastewater.

\section{Acknowledgments}

The authors gratefully acknowledge colleagues at RAPSODEE Centre, Christine Rolland, Sylvie Del Confetto, Philippe Accart and Denis Marty, for their technical help.

\section{References}

[1] W. Suchanek, M. Yashima, M. Kakihana, M. Yoshimura, Hydroxyapatite ceramics with selected sintering additives, Biomaterials 18 (1997) 923-933.

[2] T. Saeki, A new type of $\mathrm{CO}_{2}$ gas sensor comprising porous hydroxyapatite ceramics, Sensor. Actuat. 15 (1998) 145-151.

[3] T. Kawasaki, Hydroxyapatite as a liquid chromatographic packing, J. Chromatogr. 544 (1991) 147-184.

[4] G.G. Markov, I.G. Ivanov, Hydroxyapatite column chromatography in procedures for isolation of purified DNA Anal. Biochem. 59 (1974) 555-563.

[5] M. Spencer, Hydroxyapatite for chromatography II. Sources of variability and improved methods of preparation, J. Chromatogr. 166 (1978) 435-446.

[6] C. Boucetta, M. Kacimi, A. Ensuque, J.Y. Piquemal, F. Bozon-Verduraz, M. Ziyad, Oxidative dehydrogenation of propane over chromium-loaded calciumhydroxyapatite, Appl. Catal. A Gen. 356 (2009) 201-210.

[7] T. Tsuchida, T. Yoshioka, S. Sakuma, T. Takeguchi, W. Ueda, Synthesis of biogasoline from ethanol over hydroxyapatite catalyst, Ind. Eng. Chem. Res. 47 (2008) 1443-1452.

[8] A. Nzihou, P. Sharrock, Role of phosphate in the remediation and reuse of heavy metal polluted wastes and sites, Waste Biomass Valor 1 (2010) 163-174.

[9] Y. Daniels, S.D. Alexandratos, Design and synthesis of hydroxyapatite with organic modifiers for application to environmental remediation, Waste Biomass Valor 1 (2010) 157-162.

[10] M.P. Ferraz, F.J. Monteiro, C.M. Manuel, Hydroxyapatite nanoparticles: a review of preparation methodologies, J. Appl. Biomater. Biomech. 2 (2004) 74-80. 
[11] E. Lerner, R. Azoury, S. Sarig, Rapid precipitation of apatite from ethanol-water solution, J. Cryst. Growth 97 (1989) 725-730.

[12] C. Verwilghen, Fixation des métaux lourds par des phosphates de calcium dans le traitement des fumées d'Usines d'Incinération d'Ordures Ménagères, Thesis of University Toulouse III, France, 2006.

[13] C. Verwilghen, S. Rio, A. Nzihou, D. Gauthier, G. Flamant, Preparation of high specific surface area hydroxyapatite for environmental applications, J. Mater. Sci. 42 (2007) 6062-6066.

[14] C.Z. Liu, Synthesis of collagen/nano-hydroxyapitate scaffold for tissue engineering, J. Bionic Eng. 5 (2008) 1-8.

[15] V. Stanica, S. Dimitrijevic, J. Antic-Stankovic, M. Mitric, B. Jokic, I.B. Plecas, S. Raicevic, Synthesis, characterization and antimicrobial activity of copper and zinc-doped hydroxyapatite nanopowders, Appl. Surf. Sci. 256 (2010) 6083-6089.

[16] M.C. Chang, Organic-inorganic interaction between hydroxyapatite and gelatin with the aging of gelatin in aqueous phosphoric acid solution, J. Mater. Sci. Mater. Med. 19 (2008) 3411-3418.

[17] B. Boonchom, Parallelogram-like microparticles of calcium dihydrogen phosphate monohydrate $\left(\mathrm{Ca}\left(\mathrm{H}_{2} \mathrm{PO}_{4}\right)_{2} \cdot \mathrm{H}_{2} \mathrm{O}\right)$ obtained by a rapid precipitation route in aqueous and acetone media, J. Alloys Compd. 482 (2009) 199-202.

[18] M. Landin, R.C. Rowe, P. York, Particle size effects on the dehydration of dicalcium phosphate dihydrate powders, Inter. J. Pharm. 104 (1994) $271-275$.

[19] D.W. Kim, I.S. Cho, J.Y. Kim, H.L. Jang, G.S. Han, H.S. Ryu, H. Shin, H.S. Jung, H. Kim, K.S. Hong, Simple large-scale synthesis of hydroxyapatite nanoparticles: in situ observation of crystallization process, Langmuir 26 (2010) 384-388.

[20] P. Tang, Y. Zhao, F. Xia, Thermal behaviors and heavy metal vaporization of phosphatized tannery sludge in incineration process, J. Environ. Sci. 20 (2008) 1146-1152.

[21] J.C. Elliott, Studies in Inorganic Chemistry 18: Structure and Chemistry of the Apatites and Other Calcium Orthophosphates, Elsevier, Amsterdam-London -New York-Tokyo, 1994, pp. 9-29.

[22] H. El Feki, I. Khattech, M. Jemal, C. Rey, Décomposition thermique d'hydroxyapatites carbonatées sodées, Thermochim. Acta 237 (1994) 99-110.

[23] S. Peroos, Z. Du, N. Henriette de Leeuw, A computer modelling study of the uptake, structure and distribution of carbonate defects in hydroxy-apatite, Biomaterials 27 (2006) 2150-2161.

[24] M.E. Fleet, X. Liu, Carbonate apatite type A synthesized at high pressure: new space group (P3) and orientation of channel carbonate ion, J. Solid State Chem. 174 (2003) 412-417.

[25] W.L. Suchanek, P. Shuk, K. Byrappa, R.E. Riman, K.S. TenHuisen, V.F. Jana, Mechanochemical-hydrothermal synthesis of carbonated apatite powders at room temperature, Biomaterials 23 (2002) 699-710.

[26] M.E. Fleeta, X. Liu, Local structure of channel ions in carbonate apatite, Biomaterials 26 (2005) 7548-7554.

[27] D.S. Gouveia, A.H.A. Bressiani, J.C. Bressiani, Phosphoric acid rate addition effect in the hydroxyapatite synthesis by neutralization method, Mater. Sci. Forum 530-531 (2006) 593-598.
[28] R.M. Wilson, J.C. Elliott, S.E.P. Dowker, R.I. Smith, Rietveld structure refinement of precipitated carbonate apatite using neutron diffraction data, Biomaterials 25 (2004) 2205-2213.

[29] G. Cama, F. Barberis, M. Capurro, L. Di Silvio, S. Deb, Tailoring brushite for in situ setting bone cements, Mater. Chem. Phys. 130 (2011) 1139-1145.

[30] S. Baillez, A. Nzihou, D. Bernache-Assolant, E. Champion, P. Sharrock, Removal of aqueous lead ions by hydroxyapatites: equilibria and kinetic processes, J. Hazard. Mater. A139 (2007) 443-446.

[31] S. Baillez, A. Nzihou, E. Beche, G. Flamant, Removal of lead (Pb) by hydroxyapatite sorbent, Process Saf. Environ. Protect. 82 (2004) 175-180.

[32] Y.S. Ho, G. McKay, Pseudo-second order model for sorption processes, Process Biochem. 34 (1999) 451-465.

[33] I. Smiciklas, A. Onjia, S. Raicevic, Đ. Janackovic, M. Mitric, Factors influencing the removal of divalent cations by hydroxyapatite, J. Hazard. Mater. 152 (2008) 876-884.

[34] Q.Y. Ma, T.J. Logan, S.J. Traina, J.A. Ryan, Effects of $\mathrm{NO}_{3}^{-}, \mathrm{Cl}^{-}, \mathrm{F}^{-}, \mathrm{SO}_{4}^{2-}$, and $\mathrm{CO}_{3}^{2-}$ on $\mathrm{Pb}^{2+}$ immobilization by hydroxyapatite, Environ. Sci. Technol. 28 (1994) $408-418$.

[35] I.L. Shashkova, N.V. Kitikova, A.I. Rat'ko, A.G. D'yachenko, Preparation of calcium and magnesium hydrogen phosphates from natural dolomite and their sorptive properties, Inorg. Mater. 36 (2000) 826-829.

[36] E. Mavropoulos, A.M. Rossi, A.M. Costa, C.A. Perez, J.C. Moreira, M. Saldanha, Studies on the mechanisms of lead immobilization by hydroxyapatite, Environ. Sci. Technol. 36 (2002) 1625-1629.

[37] A. Kongsuwan, P. Patnukao, P. Pavasant, Binary component sorption of $\mathrm{Cu}(\mathrm{II})$ and $\mathrm{Pb}$ (II) with activated carbon from Eucalyptus camaldulensis Dehn bark, J. Ind. Eng. Chem. 15 (2009) 465-470.

[38] F. Boudrahem, F. Aissani-Benissad, H. Ait-Amar, Batch sorption dynamics and equilibrium for the removal of lead ions from aqueous phase using activated carbon developed from coffee residue activated with zinc chloride, J. Environ. Manage. 90 (2009) 3031-3039.

[39] X. Ren, D. Shao, S. Yang, J. Hu, G. Sheng, X. Tan, X. Wang, Comparative study of $\mathrm{Pb}$ (II) sorption on XC-72 carbon and multi-walled carbon nanotubes from aqueous solutions, Chem. Eng. J. 170 (2011) 170-177.

[40] D. Mohan, C.U. Pittman, M. Bricka, F. Smith, B. Yancey, J. Mohammad, P.H Steele, M.F. Alexandre-Franco, V. Gómez-Serrano, H. Gong, Sorption of arsenic, cadmium, and lead by chars produced from fast pyrolysis of wood and bark during bio-oil production, J. Colloid Interface Sci. 310 (2007) 57-73.

[41] E.E. Laney, J.H. Lee, J.S. Kim, X. Huang, Y. Jang, H.S. Hwang, T. Hayashita, R.A Bartsch, Sorption of lead(II) by proton-ionizable polyether resins, React. Funct. Polym. 36 (1998) 125-134.

[42] M.H. Entezari, T.R. Bastami, Sono-sorption as a new method for the removal of lead ion from aqueous solution, J. Hazard. Mater. B137 (2006) 959-964.

[43] S. Oh, M.Y. Kwak, W.S. Shin, Competitive sorption of lead and cadmium onto sediments, Chem. Eng. J. 152 (2009) 376-388.

[44] N. Martinez-Villegas, L.Ma. Flores-Velez, O. Dominguez, Sorption of lead in soil as a function of pH: a study case in Mexico, Chemosphere 57 (2004) 1537-1542. 